\title{
Temperature, precipitation, ozone pollution, and daily fatal unintentional injuries in Jiangsu Province, China during 2015-2017
}

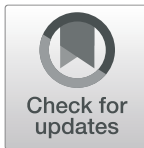

Leon S. Robertson ${ }^{1 *}$ (D) Lian Zhou ${ }^{2}$ and Kai Chen ${ }^{3}$

\begin{abstract}
Background: The correlation of unintentional injury mortality to rising temperatures found in several studies could result from changes in behavior that increases exposure to hazards or risk when exposed. Temperature, precipitation and air pollutants may contribute to symptoms and distractions that increase risk or avoidance behavior that reduces risk. This study examines data that allows estimates of the relation of daily maximum temperature, precipitation and ozone pollution to injury mortality risk, each corrected statistically for the correlation with the others.
\end{abstract}

Methods: Daily data on unintentional injury deaths and exposures to temperature, precipitation and ozone in 9 cities in Jiangsu Province, China during 2015-2017 were analyzed using Poisson regression. The regression estimates were adjusted for weekends, holidays, an anomalous difference in death rates in Nanjing, and population size.

Results: Non transport injury death risk increased substantially in relation to higher temperatures when temperatures were in the moderate range and even more so at temperatures 35 degrees (C) and higher. Transport deaths were related to increasing deaths when temperatures were low but the correlation reversed at higher temperatures. Deaths were lower on rainy days when temperatures were cool and moderate with the exception of non-transport injuries when temperatures were moderate. Higher ozone concentrations were associated with more deaths except when temperatures were low.

Conclusions: The variations in deaths in relation to temperature, precipitation and ozone suggest that people are behaving differently or are in different environments when specific combinations of the predictor variables are prevalent, putting them at greater or less risk. More study of the behaviors and circumstances that result in injury under those conditions is needed.

Keywords: Unintentional injury mortality, Temperature, Air pollution, Avoidance behavior

\footnotetext{
*Correspondence: leon.robertson@yale.edu

${ }^{1}$ Yale University School of Public Health, 60 College Street, New Haven, CT 06520-8034, USA

Full list of author information is available at the end of the article
}

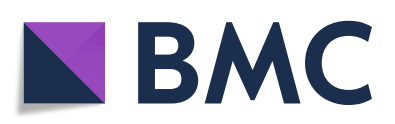

(- The Author(s). 2020 Open Access This article is licensed under a Creative Commons Attribution 4.0 International License, which permits use, sharing, adaptation, distribution and reproduction in any medium or format, as long as you give appropriate credit to the original author(s) and the source, provide a link to the Creative Commons licence, and indicate if changes were made. The images or other third party material in this article are included in the article's Creative Commons licence, unless indicated otherwise in a credit line to the material. If material is not included in the article's Creative Commons licence and your intended use is not permitted by statutory regulation or exceeds the permitted use, you will need to obtain permission directly from the copyright holder. To view a copy of this licence, visit http://creativecommons.org/licenses/by/4.0/. The Creative Commons Public Domain Dedication waiver (http://creativecommons.org/publicdomain/zero/1.0/) applies to the data made available in this article, unless otherwise stated in a credit line to the data. 


\section{Background}

Temperature, precipitation and air pollution may affect risk of injury in two ways: behavior changes that increase or decrease exposure to potentially injurious energy or increased risk if exposed. A review of the literature on the correlation of various types of injuries to ambient temperature noted that most studies focused on the association of injuries with extreme temperatures but those that studied temperature in normal ranges also found increased injury incidence and mortality rates associated with warmer temperatures (Kampe et al. 2016). Comparisons among U.S. states indicate increased injury mortality risk associated with warmth above normal (Parks et al. 2020). Research on police-reported road collisions in Spain found a 2.9\% increase during heat waves (Basagana 2015). While peoples' attention to tasks at hand may be distracted by extreme temperatures, the more likely explanation for much of the correlation is changes in human activity based on temperature and precipitation that expose them to greater or less environmental hazards. Although certain recreational activities, such as skiing, are more frequent on colder days, many others, such as swimming and boating are warm and dry weather activities. Outdoor construction and other projects are sometimes suspended because of inclement weather. Higher temperatures increase risk for cocaine users (Marzuk et al. 1998) but not as high as once thought (Bohnert et al. 2010). The correlation of temperature to drug overdoses could also partly be the result of addicts being more often under the watch of families or other persons who care for them on cold or wet days that inhibit freedom of movement.

A study of road deaths among urban cities and counties in the U.S. found that reversal of the decreasing road death trend during 2015 was mainly associated with increased temperatures in that year (Robertson 2018a). An alternative hypothesis that economic recovery from the Great Recession of 2008-2009 explained the reversal was not confirmed by comparing data among U.S. states during 2000-2016 (Robertson 2018b). In both studies, increases in vehicle travel were found in relation to increasing temperature. Road use by pedestrians and bicyclists likely increased as well. Researchers noting the increase in injury deaths in Chinese cities during the latter half of the twentieth Century repeated without evidence the conventional wisdom that they are mainly the result of activities associated with rapid economic growth (Zhou 2012). From 2010 to 2015, however, injury death rates in Chinese cities were substantially lower than in the 1980s and 1990s while economic growth remained high (Ozanne-Smith and Li 2018).

Environmental conditions other than temperature and precipitation may increase or decrease injury risk to those exposed and may also alter the probability of exposure (Sager 2019). Air pollution is irritating to the eyes and may impair vision as well as lead to coughing spasms and breathing problems especially among the asthmatic, all of which would distract from alertness. Sleepiness has been associated with air pollutants (Heyes and Zhu 2019). Performance on verbal and mathematics tests is reduced among those exposed to higher ranges of air pollutants (Zhang et al. 2018). Attempts to reduce exposure to pollutants may lead to more sedentary activities that lower risk of injury (Bresnahan et al. 1997). Studies of avoidance behavior in relation to pollution find that some people stay indoors when the air has higher concentrations of pollutants, particularly when there are broadcast, print and internet warnings of hazard to health. Smog alerts in California were related to less attendance at studied outdoor venues (Neidell 2008). School absences in Texas were found related to higher concentration of air pollutants (Curry et al. 2009) which could be due to both increased illness and avoidance behavior. Adults with asthma change their activities in response to changes in relatively low levels of ozone in the environment (Eiswerth et al. 2005).

The purpose of this paper is to report analysis of the extent to which daily fluctuations in temperature, precipitation and ozone concentrations were related to the daily counts of fatal injury during 2015 through 2017 in nine cities located in Jiangsu Province, China. While the analysis of injury deaths in correlation with these factors does not specify the extent of avoidance behavior versus risk when exposed, the analysis does quantify the likely net effect of these two factors and, in the instances of negative correlations, suggests that avoidance behavior reduces the overall risk.

\section{Methods}

Daily injury deaths during 2015-2017 in each of 9 cities in Jiangsu Province, China were provided by the Jiangsu Provincial Center for Disease Prevention and Control. The deaths were specified as occurring in transport or other circumstances. This classification was based on the International Statistical Classification of Diseases and Related Health Problems 10th Revision (ICD-10) codes V00-V99 for transport cases and W00-W99 for other unintentional cases (ICD10Data.com 2019). As of 2013, 96.5\% of transport deaths in China were from road injuries (Zhou et al. 2016).

Daily meteorological data from each city, including daily maximum, minimum and average temperatures, and precipitation, were obtained from the China Meteorological Data Sharing Service System. Daily city-level air pollution data during 2015-2017 were collected from the National Air Pollution Monitoring System, whose quality was assured by the Ministry of Ecology and Environment of China. A tornado in Yancheng June 23, 
2016 killed about 100 people in one day. These were excluded to prevent a skewed death distribution from a rare event. Data on the yearly population of each city was obtained from the Jiangsu Statistical Yearbooks (2015-2017).

Graphs of death rates per billion person days of exposure to each degree of maximum daily temperature were examined for evidence of nonlinearity. Based on the nonlinearity of deaths in relation to temperature, shown in the results section, separate Poisson regression models were fitted for temperatures below 25 degrees, 25-34 degrees and 35+ degrees $(C)$. To reduce the skew of the distributions of precipitation, and ozone $\left(\mathrm{O}_{3}\right)$, the square root of precipitation and the natural logarithm of ozone were used in the analysis.

The form of the regression equation is:

$$
\begin{aligned}
\text { Deaths }= & \text { Intercept }+\left(\mathrm{b}_{1} \mathrm{x} \text { temperature }\right) \\
& +\left(\mathrm{b}_{2} \mathrm{x} \sqrt{\text { precipitation }}\right)+\left(\mathrm{b}_{3} \mathrm{x} \log \left(\mathrm{O}_{3}\right)\right) \\
& +\left(\mathrm{b}_{4} \times \text { weekend }\right)+\left(\mathrm{b}_{5} \times \text { holiday }\right) \\
& +\left(\mathrm{b}_{6} \times \text { Nanjing }\right)
\end{aligned}
$$

where weekend is 1 if a Saturday or Sunday that is not indicated as a workday on the Chinese holiday calendar (timeanddate.com 2020), and holiday is 1 if a holiday, otherwise zero. The calendar indicates a few weekend days as workdays. The weekend and holiday variables were added to adjust for the likelihood that travel is different and workplace exposures are reduced on nonworkday weekend days and holidays. Nanjing was included as 1 if Nanjing and 0 otherwise because that city had a substantially lower death rate per population unrelated to the predictor variables. "Deaths" is the death count for each day in each city during three years. The average deaths per day were 3.2 transport injuries and 4.4 other injuries. Log (population) was included as an offset variable to correct for differences in population size among the cities.

\section{Results}

Table 1 presents the injury deaths per million inhabitants per year by external cause (transport vs. other) and in total for each city. In many instances, Nanjing's rate is less than half that of 8 of the 9 other cities. The three year upward trend in total injury death rates in several cities is mainly due to unintentional injuries other than those experienced in transport.

Table 2 gives the means and standard deviations of the weather and pollution variables by city. Nanjing is not consistently higher or lower on the predictor variables. These findings led to the decision to include Nanjing as a separate variable in the analysis.

Fig. 1 shows the transport related deaths per billion person days of exposure to specific maximum

\begin{tabular}{|c|c|c|c|c|c|c|c|c|c|}
\hline & \multicolumn{3}{|c|}{ Transport } & \multicolumn{3}{|c|}{ Other Injury } & \multicolumn{3}{|l|}{ Total } \\
\hline & 2015 & 2016 & 2017 & 2015 & 2016 & 2017 & 2015 & 2016 & 2017 \\
\hline Nanjing & 81 & 79 & 80 & 120 & 147 & 138 & 202 & 226 & 218 \\
\hline Wuxi & 115 & 115 & 112 & 273 & 315 & 314 & 387 & 430 & 426 \\
\hline Xuzhou & 228 & 224 & 221 & 183 & 197 & 231 & 411 & 421 & 452 \\
\hline Changzhou & 150 & 168 & 170 & 246 & 295 & 301 & 395 & 463 & 471 \\
\hline Nantong & 187 & 214 & 232 & 274 & 365 & 380 & 461 & 579 & 612 \\
\hline Lianyungang & 212 & 212 & 227 & 295 & 320 & 338 & 507 & 532 & 565 \\
\hline Huaian & 210 & 196 & 189 & 218 & 241 & 244 & 428 & 437 & 433 \\
\hline Yancheng & 206 & 218 & 261 & 199 & 289 & 282 & 404 & 508 & 543 \\
\hline Suqian & 162 & 179 & 183 & 137 & 151 & 180 & 299 & 330 & 364 \\
\hline
\end{tabular}

Table 1 Annual Transport and Other Fatal Unintentional Injuries Per Million Inhabitants Among Cities in Jiangsu Province, China, 2015-2017

Totals may not add exactly because of rounding

temperatures. Each data point is the sum of the deaths on the days that the maximum temperature reached the indicated degrees divided by the sum of the approximate number of people residing in a given city each day the temperature reached the indicated degrees adjusted to billions of person days. A maximum daily temperature at freezing or below in Jiangsu Province is rare. Person days when the maximum temperature was zero $(\mathrm{C})$ or less were two-tenths of $1 \%$ of the total so deaths on those days and the person years are included in the zero category in the graphs. There does not appear to an association of transport death risk with maximum temperatures other than a dip at the highest temperatures. In contrast, Fig. 2 indicates that unintentional injuries other than in transport declined slightly up to about 25 degrees maximum daily temperature, accelerated upward at higher temperatures and did so extraordinarily at temperatures above 34 degrees.

Table 2 Means and Standard Deviations of Transformed Predictor Variables

\begin{tabular}{llll}
\hline & $\begin{array}{l}\text { Temperature }\left({ }^{\circ} \mathrm{C}\right) \\
\text { Mean (SD) }\end{array}$ & $\begin{array}{l}\text { Precipitation }(\mathrm{mm}) \\
\text { Mean (SD) }\end{array}$ & $\begin{array}{l}\text { Ozone }\left(\mu \mathrm{g} / \mathrm{m}^{3}\right) \\
\text { Mean }(\mathrm{SD})\end{array}$ \\
\hline Nanjing & $21.2(9.1)$ & $1.3(2.7)$ & $4.6(0.4)$ \\
Wuxi & $21.5(9.1)$ & $0.4(2.6)$ & $4.6(0.5)$ \\
Xuzhou & $20.5(9.6)$ & $0.9(1.9)$ & $4.5(0.4)$ \\
Changzhou & $21.4(9.2)$ & $1.5(2.6)$ & $4.5(0.5)$ \\
Nantong & $20.9(8.9)$ & $1.4(2.6)$ & $4.5(0.5)$ \\
Lianyungang & $19.6(9.4)$ & $0.8(1.9)$ & $4.6(0.4)$ \\
Huaian & $20.3(9.2)$ & $1.1(2.2)$ & $4.6(0.4)$ \\
Yancheng & $20.0(9.1)$ & $1.2(2.4)$ & $4.6(0.4)$ \\
Suqian & $20.4(9.3)$ & $0.9(2.1)$ & $4.6(0.3)$ \\
\hline
\end{tabular}




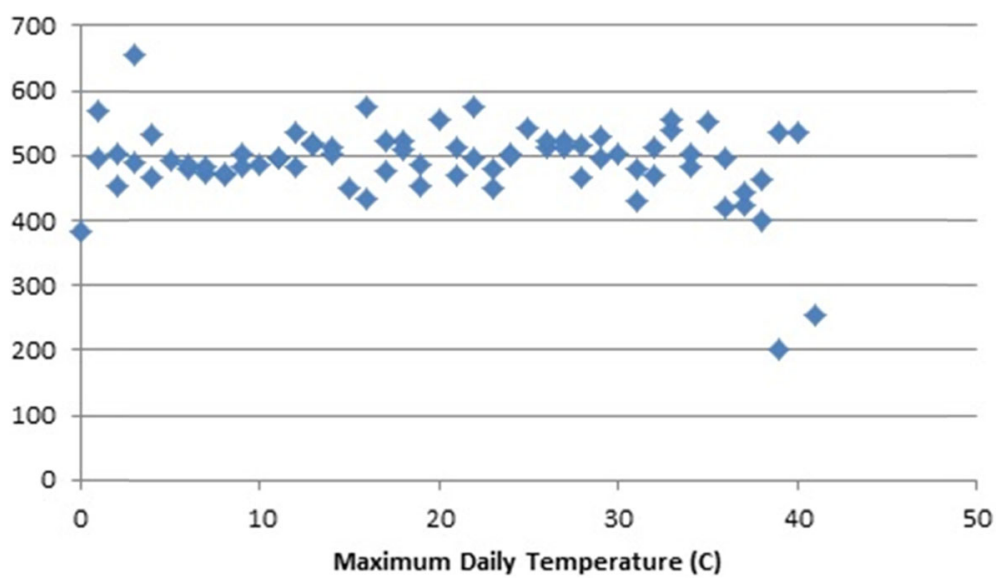

Fig. 1 Maximum Daily Temperature (C) and Transport Deaths Per Billion Person Days of Exposure, Jiangsu Province, China, 2015-2017

These findings led to the decision to analyze the data separately for cool $(<25$ degrees), moderate $(25-34$ degrees) and hot (35 plus degrees) temperatures.

The Poisson regression coefficients are presented in Table 3 along with $95 \%$ confidence intervals and criteria for goodness of fit. Both transport and other fatal injuries are consistently lower for residents of Nanjing. Corrected for that and the estimated effects of other factors, transport deaths were related to increasing deaths when temperatures were low but the correlation reversed at higher temperatures. Non-transport injury deaths increased substantially in relation to higher temperatures when temperatures were in the moderate range and even more so at temperatures 35 degrees $(\mathrm{C})$ and higher. Deaths were lower on rainy days when temperatures were cool and moderate with the exception of non-transport injuries when temperatures were moderate. Higher ozone concentrations were associated with more deaths except when temperatures were low. Transport fatalities were consistently lower on weekends and on holidays at high and low temperatures. Other injury deaths were higher on holidays when temperatures were low to moderate.

Of concern in use of regression coefficients is the degree to which the predictor variables are correlated. The squared OLS correlation coefficients among the predictor variables are displayed in Table 4. None of the correlations are high enough to be of concern. $\mathrm{O}_{3}$ is uncorrelated with precipitation and is only moderately correlated with temperature at cool temperatures and less so at moderate and high temperatures in this study. The correlation of these variables with weekends, Nanjing and population was less than 0.01. Nanjing's larger population resulted in an $\mathrm{R}^{2}$ of 0.22 with population.

\section{Discussion}

The differences in association of temperature, precipitation, pollution and fatal injury depending on temperature range is evidence of what is called "effect

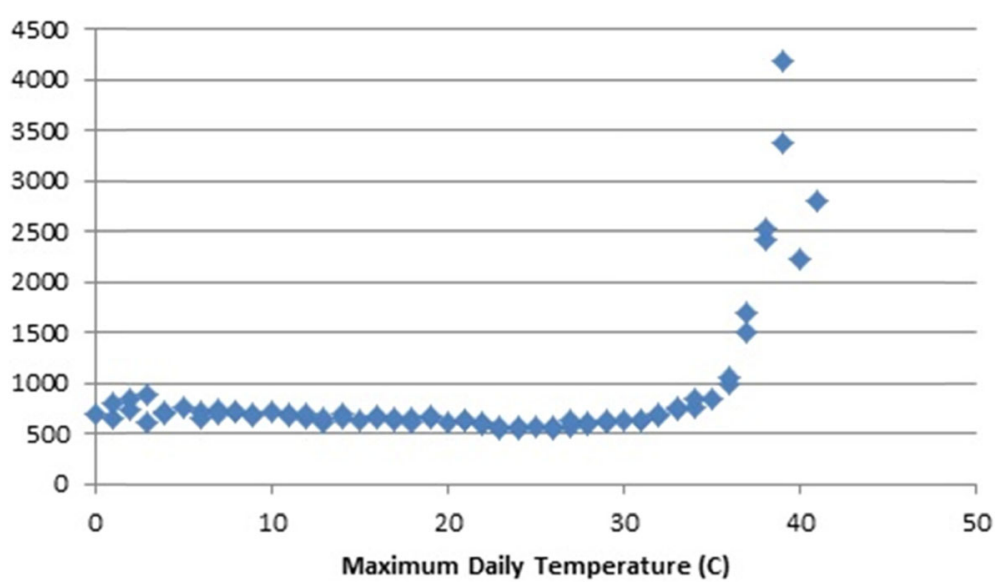

Fig. 2 Maximum Daily Temperature (C) and Unintentional Injury Deaths Other Than Transport Per Billion Person Days of Exposure, Jiangsu Province, China, 2015-2017 
Table 3 Poisson Regression Coefficients beta and 95 Percent Confidence Intervals (Cl): Unintentional Injury Fatalities Per Day

\begin{tabular}{|c|c|c|c|c|c|c|}
\hline \multicolumn{7}{|c|}{ Transport Deaths } \\
\hline \multirow[t]{2}{*}{ Temperature } & \multicolumn{2}{|c|}{$\mathrm{Cool}\left(<25^{\circ} \mathrm{C}\right)$} & \multicolumn{2}{|c|}{ Moderate $\left(25-34^{\circ} \mathrm{C}\right)$} & \multicolumn{2}{|c|}{$\operatorname{Hot}\left(>34^{\circ} \mathrm{C}\right)$} \\
\hline & Beta & $95 \% \mathrm{Cl}$ & beta & $95 \% \mathrm{Cl}$ & beta & $95 \% \mathrm{Cl}$ \\
\hline Temperature & -.0077 & $(.0050, .0104)$ & -.0074 & $(-.0145,-.0003)$ & -.0796 & $(-.1202,-.0334)$ \\
\hline$\sqrt{ }$ Precipitation & -.0189 & $(-.0260,-.0118)$ & -.0129 & $(-0.0209,-.0049)$ & -.0031 & $(-.0365, .0303)$ \\
\hline Log (ozone) & -.1263 & $(-.1681,-.0845)$ & 0.0563 & $(.0000, .1126)$ & -.1995 & $(-.0061,-.3929)$ \\
\hline Weekend & -.0531 & $(-.0862,-.0120)$ & -.0534 & $(-.0959,-.0109)$ & -.1793 & $(-.3019,-.0567)$ \\
\hline Holiday & -.0863 & $(-.1441,-.0285)$ & .0765 & $(.0094, .1435)$ & -.3979 & $(-.7640,-.0318)$ \\
\hline Nanjing & -.8241 & $(-.8827,-.7655)$ & -.9118 & $(.9898,-.8338)$ & -.7803 & $(-.9695,-.5911)$ \\
\hline Intercept & -13.9409 & & -14.4360 & & -12.6328 & \\
\hline Deviance/df & 1.35 & & 1.37 & & 1.39 & \\
\hline \multicolumn{7}{|c|}{ Other Unintentional Injury Deaths } \\
\hline \multirow[t]{2}{*}{ Temperature } & \multicolumn{2}{|c|}{$\mathrm{Cool}\left(<25^{\circ} \mathrm{C}\right)$} & \multicolumn{2}{|c|}{ Moderate $\left(25-34^{\circ} \mathrm{C}\right)$} & \multicolumn{2}{|c|}{ Hot $\left(>34^{\circ} \mathrm{C}\right)$} \\
\hline & beta & $95 \% \mathrm{Cl}$ & beta & $95 \% \mathrm{Cl}$ & beta & $95 \% \mathrm{Cl}$ \\
\hline Temperature & -.0045 & $(-.0068,-.0021)$ & .0314 & $(.0251, .0377)$ & .2277 & $(.2037, .2517)$ \\
\hline$\sqrt{ }$ Precipitation & -.0170 & $(-.0233,-.0107)$ & .0095 & $(.0026, .0164)$ & .0101 & $(-.0313, .0111)$ \\
\hline Log (ozone) & -.1586 & $(-.1945,-.1227)$ & .0248 & $(-.0248, .0744)$ & .1788 & $(.0536, .3040)$ \\
\hline Weekend & -.0051 & $(-.0337, .0235)$ & -.0146 & $(-.0524, .0232)$ & -.0325 & $(-.1034, .0384)$ \\
\hline Holiday & -.0269 & $(-.0211,-.0749)$ & .0208 & $(-.0415, .0831)$ & .2220 & $(-.4780, .0380)$ \\
\hline Nanjing & -.6288 & $(-.6758,-.5817)$ & -.6376 & $(-.6996,-.5756)$ & -.6667 & $(-.7728,-.5606)$ \\
\hline Intercept & \multicolumn{2}{|l|}{-13.3868} & \multicolumn{2}{|l|}{-15.2458} & \multicolumn{2}{|l|}{-22.6963} \\
\hline Deviance/df & \multicolumn{2}{|l|}{1.35} & \multicolumn{2}{|l|}{1.40} & \multicolumn{2}{|l|}{3.18} \\
\hline
\end{tabular}

The criteria for goodness of fit are near 1 indicating good fit of the models

modification", also found in research on non-injury mortality in relation to temperature and air pollutants (Chen et al. 2018). These results are mostly consistent with previous studies showing increased risk of unintentional injury mortality as temperatures rise, particularly when maximum daily temperatures are above 25 degrees (C). A major exception in Jiangsu Province is that the risk of death in relation to rising temperatures is mainly confined to people engaged in activities other than transport. While the results are correlations with the usual concern that they may not represent causation, the cited literature in the introduction suggests that people adjust their activities to pollution and it is common knowledge that they do so in response to weather.

The results are unlikely to be the result of confounding by unmeasured variables. Confounding occurs when an unmeasured variable causes both predictor and outcome variables resulting in their being correlated without one causing the other. The causes of variations in temperature and precipitation are unlikely to influence mortality risk. Workers in industries that increase pollution may be at greater risk of fatal injury but the correlation of increases in ozone to injury is negative at low temperatures.

A major limitation of this study is lack of observations of actual behavior under the conditions correlated to mortality. More research is needed on observed behavior in relation to temperature, precipitation and concentration of pollutants. What are people doing that exposes them to the energy (or lack thereof in the cases of drowning and asphyxiation) at varying temperatures, on rainy days or when pollution is higher? Why would warmer temperatures be related to transport casualties in Spain and fatalities in U.S. cities much more strongly

Table 4 Squared OLS Correlation Coefficients Among Transformed Daily Weather and Pollution Predictor Variables At Cool, Moderate and Hot Temperatures, Jiangsu Province, China. 2015-2017

\begin{tabular}{lccccc}
\hline & Cool & & Moderate & & Hot \\
& Precipitation & Ozone & Precipitation & Ozone & Precipitation \\
\hline Temperature & 0.04 & 0.21 & $<0.01$ & 0.01 & $<0.01$ \\
Precipitation & & $<0.0$ & & 0.11 & 0.04 \\
\hline
\end{tabular}


than in cities in Jiangsu Province, China? One possible reason is the difference in cultures regarding vehicle use. U.S. road deaths are substantially higher on Friday and weekend days than on other weekdays (Bureau of Transportation Statistics 2019). In contrast, transport deaths in Jiangsu Province are 3 \% less on Saturday and 6 \% less on Sunday than on the average weekday. This suggests that vehicles are used less for discretionary travel in Jiangsu Province. Also, a substantial proportion of the correlation of temperature and road death risk in the U.S. is due to the apparent lack of use of bicycles and motorcycles at subfreezing temperatures (Robertson 2018b). Such temperatures are extremely rare during daytime in Jiangsu Province.

Unfortunately, we have no data on kilometers travelled per vehicle in China or pedestrian volume and bicycle use in the U.S. and Chinese cities. If there were major road injury prevention efforts during 2015-2017 in Jiangsu Province, they could have offset the effect of temperature. According to one report, China has made little use of "traffic calming" road designs that have reduced fatality rates in other countries but does have engineering standards for vehicle crashworthiness, child safety seats and school bus seats (Fayard 2017). A seat belt use law was imposed throughout China in May, 2004. A study if belt use observed in traffic in Nanjing soon after the law indicated about $67 \%$ use by drivers and $19 \%$ by front seat passengers (Routley et al. 2007). During 2005-2007, belt use by drivers in Nanjing had declined to $39 \%$ and that of front seat passengers to $3 \%$ leaving substantial room for improvement (Routley et al. 2008). A study of road deaths in Jiangsu Province during 2012 found that more than half the deaths occurred to pedestrians and that the risk of pedestrian deaths per population increased dramatically with age (Ding et al. 2017) but the age distribution of the population would not have changed enough in three years to affect the results reported here. A search of Chinese laws and regulations aimed at childhood injury prevention relative to laws and regulations recommended by the United Nations Children's Fund, the World Health Organization or the European Child Safety Alliance found that 10 of 27 were not found in Chinese statutes and regulations (Li et al. 2015).

The results regarding the possible effects of ozone concentrations suggest that avoidance behavior may reduce injury risk at low temperatures but the net effect of more pollution during days of moderate and high temperatures is increased injury risk. The lower deaths on rainy days are suggestive of avoidance behavior.

We have no data that informs the reasons for the lower death rates in Nanjing. Study of the differences in local injury prevention efforts in that city compared to the others might reveal measures that could be applied elsewhere.

\section{Conclusions}

The association of warming and injury mortality varies from country to country depending on the temperature ranges experienced, cultural factors and behavioral responses to temperature, precipitation and air pollution. With a few exceptional circumstances, warming temperatures are associated with increased risk of unintentional injury mortality. Without further efforts at prevention based on data regarding the types and circumstances of injuries affected, climate warming will likely contribute to an upward trend in injury mortality. Burning fossil fuels that contribute to warming and air pollution continues to grow, outpacing the adoption of sustainable energy sources (United Nations Environment Programme 2019).

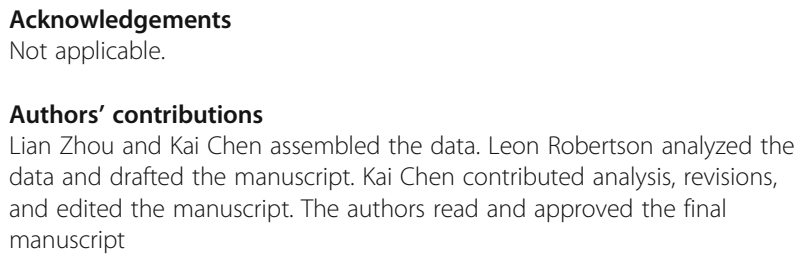

Consent for publication

The authors agree on submission for publication.

\section{Competing interests}

The authors have no financial or other interests that would be altered by publication of this study.

\section{Author details}

${ }^{1}$ Yale University School of Public Health, 60 College Street, New Haven, CT 06520-8034, USA. ${ }^{2}$ Jiangsu Provincial Center for Disease Prevention and Control, 172 Jiangsu Road, Nanjing 21009, Jiangsu, China. ${ }^{3}$ Yale Center on Climate Change and Health, Yale University School of Public Health, 60 College Street, New Haven, CT 06520-8034, USA.

Received: 8 April 2020 Accepted: 19 June 2020

Published online: 27 July 2020

\section{References}

Basagana X. High ambient temperatures and risk of motor vehicle crashes in Catalonia, Spain (2000-2011): a time-series analysis. Environ Health Persp. 2015;123:1309-16.

Bohnert ASB, et al. Ambient temperature and risk of death from accidental drug overdose in New York City, 1990-2006. Addiction. 2010;105:1049-54.

Bresnahan BW, et al. Averting behavior and urban air pollution. Land Econ. 1997; 73:340-57.

Bureau of Transportation Statistics. Motor Vehicle Fatal Crashes by Day of Week, Time of Day, and Weather and Light Conditions. U.S. Department of Transportation. 2019. https://www.bts.gov/content/motor-vehicle-fatalcrashes-day-week-time-day-and-weather-and-light-conditions. Accessed 17 Nov 2019.

Chen $\mathrm{K}$, et al. Two-way effect modifications of air pollution and air temperature on total natural and cardiovascular mortality in eight European urban areas. Environ.Internat. 2018;116:186-96. 
Curry J, et al. Does pollution increase school absences? Rev Econ Stat. 2009;91: 682-94.

Ding $Y$, et al. Demographic and regional characteristics of road traffic injury deaths in Jiangsu Province. China J Pub Heal. 2017;39:e79-87.

Eiswerth ME, et al. Impacts of ozone on the activities of asthmatics: revisiting the data. J Environ Manag. 2005;77:56-73.

Fayard G. Road injury prevention in China: current state and future challenges. J Pub Heal Policy. 2017:40:292-307.

Heyes A, Zhu M. Air pollution as a cause of sleeplessness: social media evidence from a panel of Chinese cities. J Environ Econ Manage. 2019;98:102247.

ICD10Data.com. https://www.icd10data.com/ICD10CM/Codes/N00-Y99. Accessed 27 Nov 2019

Jiangsu Statistical Yearbook. Chinese Statistical Press. Beijing, China, 2015-2017.

Kampe EO, Kovats S, Hajat S. Impact of high ambient temperature on unintentional injuries in high-income countries: a narrative systematic literature review. BMJ Open. 2016;6:e010399. https://doi.org/10.1136/ bmjopen-2015010399.

Li L, et al. Legislation coverage for child injury prevention in China. Bull World Healt Org. 2015;93:169-75.

Marzuk PM, et al. Ambient temperature and mortality from unintentional cocaine overdose. JAMA. 1998;179:1795-800.

Neidell MJ. Information, avoidance behavior, and health: the effect of ozone on asthma hospitalizations. J Hum Res. 2008;44:450-78.

Ozanne-Smith J, Li Q. A social change perspective on injury prevention in China. Inj. Prev. 2018;24:25-31.

Parks RM, et al. Anomalously warm temperatures are associated with increased injury deaths. Nature Med. 2020;26:65-70.

Robertson LS. Climate change, weather and road deaths. Inj Prev. 2018a;24:232-5.

Robertson LS. Reversal of the road death trend in the U.S. in 2015-2016: An examination of the climate and economic hypotheses. J. Trans Health. 2018b; 9:161-8.

Routley V, et al. Pattern of seat belt wearing in Nanjing. China Inj Prev. 2007;13: 388-93.

Routley V, et al. China belting up or down? Seat belt wearing trends in Nanjing and Zhoushan. Acc Anal Prev. 2008:40:1850-8.

Sager L. Estimating the effect of air pollution on road safety using atmospheric temperature inversions. J Environ Econ Manage. 2019;98. https://www. sciencedirect.com/science/article/pii/S0095069618301220. Accessed 13 Dec 2019.

Timeanddate.com. https://www.timeanddate.com/holidays/china/. Accessed 18 Mar 2020.

United Nations Environment Programme. Emissions gap report 2019. New York: United Nations; 2019.

Zhang $X$, et al. The impact of exposure to air pollution on cognitive performance. Proc Nat Acad Sci. 2018;115:9193-7.

Zhou J, et al. Rising mortality from injury in urban China: demographic burden, underlying causes and policy implications. Bull World Health Org. 2012;90: 461-7.

Zhou M, et al. Cause-specific mortality for 240 causes in China during 1990-2013: a systematic subnational analysis for the global burden of disease study 2013. Lancet. 2016;387:251-72.

\section{Publisher's Note}

Springer Nature remains neutral with regard to jurisdictional claims in published maps and institutional affiliations.

Ready to submit your research? Choose BMC and benefit from:

- fast, convenient online submission

- thorough peer review by experienced researchers in your field

- rapid publication on acceptance

- support for research data, including large and complex data types

- gold Open Access which fosters wider collaboration and increased citations

- maximum visibility for your research: over $100 \mathrm{M}$ website views per year

At $\mathrm{BMC}$, research is always in progress.

Learn more biomedcentral.com/submissions 